\title{
Design of Growth Baby Stroller Based on Computer Aided Innovation Technology
}

\author{
Chengming Cao \\ College of Art and Design, Guilin University of Electronic Technology, Guilin, Guangxi, Zip code: 541004
}

\begin{abstract}
Purpose: In view of the shortcomings of safety, space and service life of baby stroller in the current market, a growth type baby stroller is designed to meet the continuous needs of family children at different ages. Method: Computer aided innovation technology is used to design the growth baby strollers and improve the design goal, using TRIZ theory to find technical conflicts, that is, the similarity of product structure and the growth of infant age, single product function and children's emotional richness and using computer-aided innovation technology to solve conflicts. Conclusion: In the design of growth baby stroller, computer aided innovation technology helps designers to find the improvement priority direction of stroller design, put forward the feasible design scheme, and meet the requirements of extending the service life of products with the growth of infant age.
\end{abstract}

\section{Introduction}

CAI (Computer Aided Innovation) is a key basic technology in new product development. It is an innovative technology system based on invention problem solving theory (TRIZ), which integrates modern design methodology, computer software technology and other disciplines.[1] At present, as a powerful tool for designers at home and abroad, CAI software breaks the thinking pattern and broadens the thinking in the conceptual design stage of products in different fields, and proposes effective design schemes with high quality. The development direction of CAI is to integrate different innovative principles and thinking methods (such as associative method, brainstorm method, 5W2H method, bionic method and image thinking method, etc.) into software to strengthen its ability of assisting designers to innovate ideas. Therefore, computer aided innovation theory enables people to break the limitations that often occur when thinking about problems, reduce the blindness caused by the conjecture refutation method used in conventional inventions, and clearly find out ways and methods to solve problems. In particular, the TRIZ theory can not only improve the success rate of inventions, shorten the time spent on inventions, but also make the invention predictable.[2]

The design and use of infant strollers, originating in Europe, has been designed and used for more than three hundred years. But in China, there are only 10 to 20 years. However, according to the growth rules of infants and children, and the differences in their functions, the stroller is divided into many categories and its structural design is uniform. At present, the baby stroller products on the
Chinese market are complicated in structure, and the folding method and applicable places are limited. One hand folding is difficult, the volume after folding is bulky and storage is difficult after folding and so on. These structural folding problems bring great inconvenience to the operators and the process of expansion is also so troublesome. And a very important issue is that the baby stroller has a very short lifespan and cannot be used after the child is a little older. Therefore, it is urgent to innovate the folding structure and materials of the baby stroller to meet the needs of consumers in different situations and to increase the use of the stroller.

With the growth of the stroller, from the perspective of products, the popular interpretation is a product that can be used on the road of growth. Through proper structural design, the individual transformation mode is completed, so that the product can reach different functions and states that need to be met at each different stages. What has changed is not only the product itself, but also the lifestyle, psychological needs and emotional sustenance of the users.

\section{Using computer aided innovation technology to design growth baby stroller}

\subsection{Demand analysis}

The analysis of user demand is a key point in the early development of product design. How to obtain and analyze the demand of the product comprehensively and accurately is a key factor for the success of product design. Based on the diversity, variability and ambiguity of user 
demand, the user demand is investigated through market analysis, questionnaire survey, field visits, papers and patents.[3]

According to some data from the China Baby Stroller Market Report: According to the survey, each household has an average of 1.9 infant strollers, and more than two of them account for $70 \%$ of the surveyed households. After the general purchase, the transfer rate is $63 \%$ without major damage.

In order to reduce the transfer rate and improve the service life of the product, it is necessary to consider the changes and growth changes of the user's psychological state, and can accurately poke the pain and solve the problem. The real design is not to meet the needs expressed by the user verbally, but to refine and analyze the real needs of the user. In the design scheme, careful consideration will be given to the age stage and psychological change stage of the design, and the real demands will be extracted.

The ideal of the "growth" stroller is to give the user a way to communicate and to keep a good memory. This is an add-on to the designed product, while the potential product is designed to develop new components on the basic model of the growth stroller, creating different potential values.

Through the survey and summary, the following user demands are extracted: Ordinary strollers are not suitable for children over 4 years old; The stroller has a single function and cannot meet the functional changes as the child grows older; In terms of the protective barrier of infant stroller, $68 \%$ of consumers think that it is suitable that the barrier can be removed and adjusted. Shopping carts for baby strollers are required by $90 \%$ of consumers to have a shopping cart or bag. This makes it easy for consumers to store necessities such as baby bottles and diapers when they take babies out for a walk; In the era of the popularity of private cars, $73 \%$ of consumers want to the stroller be able to put in private cars.

\subsection{Analysis and application of growth stroller based on computer aided innovation}

The basic idea of growth stroller based on computer-aided innovation design is: Using the root cause analysis method of computer aided innovation (Figure 1, the flow chart of computer aided innovation analysis of growth baby stroller); 1) Using 5W2H analysis method to define the stage of the problem, mainly to solve the general problem of the baby stroller; 2). Using the 5why, fishbone diagram, system diagram, etc. to carry out the investigation of the baby stroller, mainly to investigate the main problems of the current baby stroller; 3 ). Identifying and evaluating the problems existing in the stroller through computer analysis tools; 4). Using TRIZ theory to carry out the optimal solution for growth stroller.

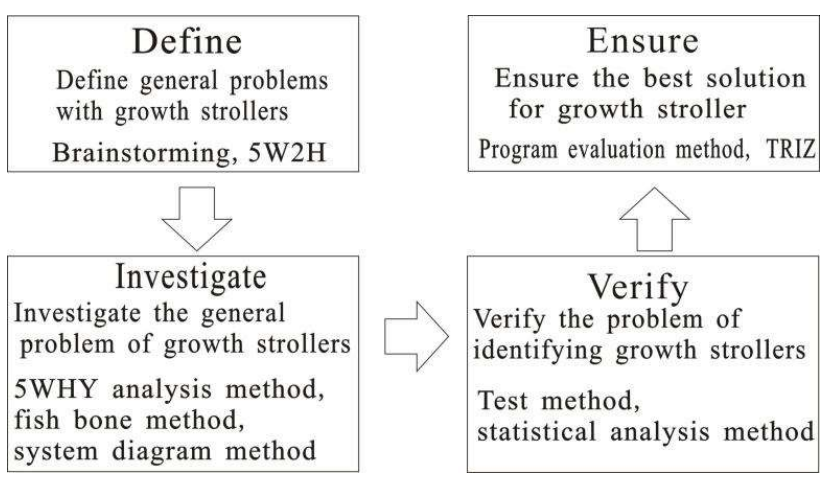

Figure 1. The flow chart of computer aided innovation analysis of growth baby stroller.

\subsection{Functional innovation design model of growth stroller based on TRIZ}

When designing the shape, function or features of the growth stroller, it may affect other aspects of the stroller. If these effects are negative, conflicts will arise. According to TRIZ theory, conflicts are common in various product designs, and the core of product innovation is to resolve conflicts in design and develop competitive products. Therefore, finding out the conflicts in innovative design and proposing solutions is the key to the innovative design of TRIZ theory combined with baby strollers.

The basic idea of using TRIZ theory for innovative design is (as shown in Figure 2, the innovative design model of the growth stroller under the application of TRIZ theory): 1) According to the TRIZ theory, conduct market research on baby stroller, analyze market demand, and find out the main problems existing in the design of baby stroller. 2) Analyze the structural characteristics of the stroller, study the innovative application of various folding methods, steering and link structures in the design, and determine the key issues that need to be solved in the innovative design. 3) Describe these problems by using 39 engineering parameters of TRIZ theory, and transform them into standard problems of TRIZ theory. 4) Determine the conflict type of TRIZ problem. Physical conflict can apply separation principle to find the invention principle to solve the problem. Technical conflict can apply Altshuller conflict matrix to find the corresponding invention principle. 5) Refine these invention principles into detailed design ideas to form innovative designs for growing stroller. 


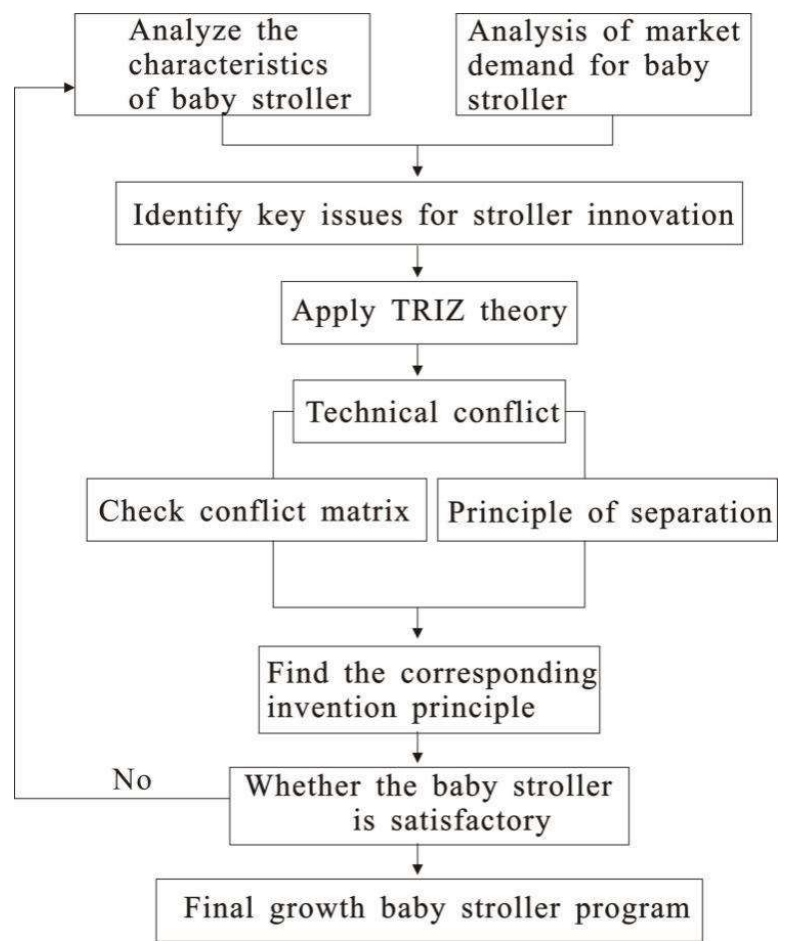

Figure 2. The innovative design model of the growth stroller under the application of TRIZ theory.

\section{The determination of the function of the growth stroller and the realization of the program}

The functional demand indicators are: comfortable performance, safe and reliable, and environmentally friendly; The psychological demand indicators are: exquisite sculpt and interesting taste. The economic demand indicators are: long-term use and good price.[4] When using the TRIZ theory to design the product's function, the product's function needs to be generally described in order to search for related products and their structures that can realize the various functions of the baby stroller in other fields, that is, to use "verb + noun" to describe the function of the product. (Table 1 Requirements of the stroller design and the corresponding invention principles) Developing the useful functions of products and avoiding harmful functions are directly related to the value and market competitiveness of products.[5]

Table 1. Requirements of the stroller design and the corresponding invention principles.

\begin{tabular}{|c|c|c|}
\hline Number & $\begin{array}{c}\text { Functional, } \\
\text { psychological and } \\
\text { economic requirements }\end{array}$ & $\begin{array}{c}\text { Corresponding } \\
\text { invention principles }\end{array}$ \\
\hline 1 & $\begin{array}{l}\text { Increase the new } \\
\text { function of baby } \\
\text { stroller }\end{array}$ & $\begin{array}{c}5 \text { Combination method, } \\
6 \text { multi - use method, } 15 \\
\text { dynamic method }\end{array}$ \\
\hline 2 & $\begin{array}{l}\text { Improve the safety of } \\
\text { baby stroller }\end{array}$ & $\begin{array}{c}3 \text { Local quality } \\
\text { improvement method, } \\
10 \text { pre-action method, } \\
11 \text { preset prevention } \\
\text { method, } 18 \text { mechanical } \\
\text { vibration }\end{array}$ \\
\hline
\end{tabular}

\begin{tabular}{|c|c|c|}
\hline 3 & $\begin{array}{c}\text { Enhance the fun of } \\
\text { baby stroller }\end{array}$ & $\begin{array}{c}14 \text { Surface, 24 use of } \\
\text { intermediary, 27 } \\
\text { replace, 32 color change }\end{array}$ \\
\hline 4 & $\begin{array}{c}\text { Stroller folding saves } \\
\text { space }\end{array}$ & $\begin{array}{c}\text { Segmentation, } 2 \\
\text { extraction, 6 versatility, } \\
17 \text { spatial dimension } \\
\text { change, 35 performance } \\
\text { conversion }\end{array}$ \\
\hline 5 & Economic demand & $\begin{array}{c}28 \text { Alternative method, } \\
40 \text { composite materials }\end{array}$ \\
\hline
\end{tabular}

Function-oriented search is a tool for finding functional implementation solutions in mature areas of technology development. Unlike most common search engines based on keyword search, such as Baidu and Google, function-oriented search takes behavior and objects as the starting point and generalizes functions from the more mature and advanced areas of development, looking for more reliable technical solutions for migration to solve the technical problems of new products. Solving existing problems through technology migration can make it easier, faster, more efficient, and more reliable to get product design solutions.[6]

In the functional design phase of the stroller, the stroller is reduced in space and the growth is described as a "foldable mechanism". The computer search engine is used to get the following search-oriented map (Fig. 3 Baby stroller folding search- oriented function diagram).

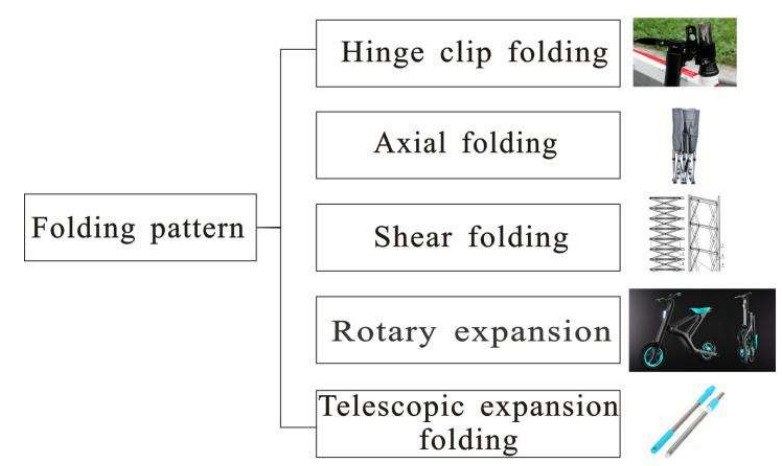

Figure 3. Baby stroller folding search- oriented function diagram.

Benchmarking analysis is to compare, analyze and evaluate the engineering system selected by the function-oriented search from the main value parameters of the system and the upgrading ability of each value parameter. To determine the ideal degree of the system, we should use the simple structure and low cost structure to realize the product function. For the folding function of the stroller, the technical solutions selected by the function-oriented search and analysis are comprehensively compared to evaluate each competitive system. The above-mentioned folding function orientation diagram is comprehensively analyzed and evaluated to obtain an optimal solution.

Feature transfer is an analytical tool used to improve foundation engineering systems and transfer related characteristics from alternative engineering systems. That is, to migrate solutions or principles to similar problems in other areas where technology has matured to address existing problems on the system.[7-8] Through the comprehensive comparison and analysis of the 
competition system, it is determined that the hinge clip folding principle is applied to the folding structure of the baby stroller to realize the growth design of the baby stroller and the transfer of characteristics (Fig. 4 Design of growth baby stroller).

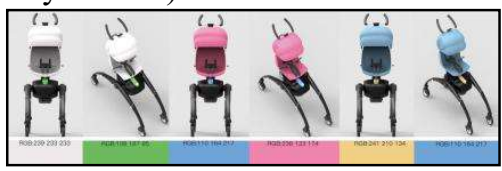

Figure 4. Design of growth baby stroller.

Through the reasonable application of the connecting rod turnover mechanism and the connecting rod spatial mechanism, combined with the sensor induction, the actuator and the joint controller start to work to drive the mechanism movement, so that the baby stroller can rotate to achieve the function transformation of the toy car, so that the baby stroller itself becomes a toy. In the process of changing the stroller, it will also be a playful state, changing the way, reversing life and enjoying the fun (Fig.5 Use effects of different stages of growth baby stroller).

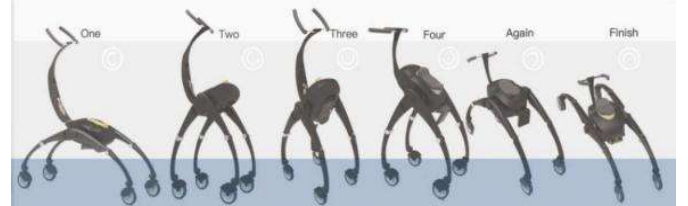

Figure 5. Use effects of different stages of growth baby stroller.

\section{Conclusion}

Many problems are found in the design process. In the market, most of the circulation is the folding and receiving design of the connecting rod mechanism, and many of the folding and receiving of the connecting rod are dangerous. In life, parents often need to embrace infants and take baby strollers. At this point, the stroller is very cumbersome. If there is a structure that can be stored with one hand and it is not dangerous, then the problem can be solved. In the course of the research, it is found that there is no gear-driven folding storage stroller in the market. Through the use of computer aided innovation, designers can be assisted to design a unique personalized folding baby stroller and use the functional orientation and benchmarking analysis of TRIZ theory to select the structural principle of the trunk and umbrella, and refine one of the key storage methods. In combination with the motion principle of the ratchet cam, a new structure, intermittent planetary gear is designed. How does it grow with the baby after the internal foundation is established? The best idea for a baby stroller to grow with is to make itself a communication toy. Being able to grow in play has a positive effect on children's future physical and mental development. In the design of the intermittent planetary gear, the structural design is expanded, and the concept mechanism of spatial linkage rotation is formed to complete the conversion of the two functions. The transformation of the toy car mode and the stroller mode enables a structurally functionally emotional design.

\section{References}

1. Guo Cailing. Research on Computer aided Innovation Platform Based on QFD/TRIZ [D]. North China Electric Power University, 2004.

2. Yang Jing. Innovative Design of Tang Rosette Pattern Fabric Souvenirs Based on TRIZ [J]. Journal of Silk, Volume 54, Issue 5, P56. 2017.05.

3. Gui Ke et al. Innovative Design of a Multipurpose Desk Based on Modern TRIZ Tools [J]. Packaging Engineering, Volume 37, Issue 14, P35.2016.07.

4. Yi Xuefeng. Improved Design for Children's Beds Based on QFD and TRIZ [J]. Packaging engineering, Volume 38, Issue 6, P247. 2017.03.

5. Cao Guozhong, Guo Haixia, Tan Runhua, etc. Research on Functional Evolution, Combination and Failure Mode for Product Function Innovation [J]. Journal of Mechanical Engineering, 2012, 48(11): 29-38.

6. LITVIN S. New TRIZ: Based Tool-Function-Oriented Search (FOS) [C]. Florence: Firenze University Press, 2004.

7. Sun Guangrui, Zhang Yachi. Emotional Design of New-Chinese-Style Furniture [J]. Furniture and interior Design, 2014(4): 11-13.

8. SOUCHKOV V. The International TRIZ Association [EB/OL]. [2015-06-06]. http://matriz.org/wp-content/uploads/2012/10 /TRIZGlossary Version1-2.pdf. 